\title{
Experiment Study on the Flocculent Deposition of Dredged Sediment in Tongji Bridge Reservoir
}

\author{
Yannan Shi, ${ }^{1, a}$, Chaojie Zhang $^{1, b}$, Taoxiao Chen ${ }^{1, \mathrm{c}}$, Jiongqi $\mathrm{Yu}^{1}$
}

1. Zhejiang Institute of Hydraulics \& Estuary, Zhejiang Hangzhou, 310020, China

asyn.0419@163.com, 'bcjie2004@126.com, cctxanyway@163.com

\begin{abstract}
Keywords: Dredged sediment; Flocculants; Settling; Supernatant liquor; Dewatering Abstract This test explored suitable flocculating settling technological parameter for dredge d sediment in Tongji Bridge Reservoir. It referred to sewage treatment plant's sludge treatm ent methods, and used PAM, PAC, $\mathrm{FeCl}_{3}, \mathrm{MgCl}_{2}, \mathrm{Na}_{2} \mathrm{CO}_{3}, \mathrm{Ca}(\mathrm{OH})_{2}$ and $\mathrm{KMnO}_{4}$ as floccula nts to improve water quality. Through single and mixed experiments, this paper studied floc culants' influence on sludge setting rate and supernatant liquor. The result shows that anioni c PAM's setting rate is faster than other flocculants, but its supernatant turbidity is high. T he effect of $\mathrm{FeCl}_{3}, \mathrm{PAC}, \mathrm{KMnO}_{4}$ is poorer than PAM, however they have better water purif ication effect. In view of sedimentation, argillaceous improvement and clarification, this pap er chooses three groups of flocculants, which are group two $\mathrm{PAM}+\mathrm{PAC}+\mathrm{MgCl}_{2}$, group three $\mathrm{PAM}+\mathrm{PAC}+\mathrm{Ca}(\mathrm{OH})_{2}$, and group four $\mathrm{PAM}+\mathrm{PAC}+\mathrm{Na}_{2} \mathrm{CO}_{3}+\mathrm{Ca}(\mathrm{OH})_{2}$. Therefore, this paper $\mathrm{c}$ an provide a simple and feasible way for the rapid dewatering of dredged sediment, which is convenient for sediment's disposal and resource utilization.
\end{abstract}

\section{Introduction}

Pujiang County Tongji Bridge Reservoir has been built more than 50 years, but never to desilting. And its water quality was increasingly serious. Through the investigation, its amount reached about 2.6 million stere. The situation of drinking water security was very grim, which was caused by endogenous pollution. And sediment dredging was effective means to clear reservoir endogenous pollution and reduce pollution load $^{[1]}$. Therefore, Pujiang County proposed desilting project in Tongji Bridge Reservoir.

With the deepening of Zhejiang Province "five water treatment", it appeared a lot of dredged sediment in a short time. Because dredged sediment had high moisture content and large volume, its dehydration technology was a key point in the process of resource utilization before processing ${ }^{[2-5]}$. At present, our country usually adopted naturally air dried to reduce the dredged sludge's volume $^{[6-7]}$, such as sediment dredging engineering in Hangzhou West Lake and Wuxi Wuli Lake ${ }^{[8-9]}$. But natural drying would take a long time, and need large bulk, and produce secondary pollution easily.

To improve efficiency, reduce reclamation covers, and ensure residual water quality, this paper put forward that dredged sediment in Tongji Bridge Reservoir were added flocculants, by means of the sewage sludge's treatment method in sewage treatment plant. It would improve residual water quality and sediment performance. It will find out the suitable technological parameter for Tongji Bridge Reservoir's sediment, and provide a reference for future similar project.

\section{Materials and Methods}

Sediment used in the experiment were took from Pujiang County Tongji Bridge Reservoir. Its natural moisture content was about $85 \%$, average grain diameter was $0.005 \mathrm{~mm}$, and its $\mathrm{pH}$ value was about 7.2, which was almost neutral. And its permeability coefficient was $1.8 \times 10^{-4}$. According to the report of Chinese Academy of Sciences, the maximum organic content of this dredged sediment was up to $20 \%$, and its clay and colloidal particle was nearly $50 \%$. So it was belong to high liquid limit clay. 
Its main instruments and equipments were an infinitely variable speed electric mixer and some $1000 \mathrm{ml}$ measuring cylinders, etc. This experiment used PAC, $\mathrm{FeCl}_{3}, \mathrm{MgCl}_{2}, \mathrm{Na}_{2} \mathrm{CO}_{3}, \mathrm{Na}_{2} \mathrm{SiO}_{3}$, $\mathrm{Ca}(\mathrm{OH})_{2}, \mathrm{CaCl}_{2}, \mathrm{KAlSO}_{4} \cdot 12 \mathrm{H}_{2} \mathrm{O}$ and $\mathrm{KMnO}_{4}$ as inorganic flocculants, and used non-ionic PAM and anionic PAM as organic flocculants.

We took different kinds and amounts of flocculating agents mixed into dredged sediment, took a certain quality, and research its setting effect. The samples were confected into $400 \%$ moisture content of mud. Its mass was calculated according to Eq. 1, 2 and 3.

$$
\begin{aligned}
& \omega^{t}=\frac{m_{15}}{m_{S}} \\
& \frac{m_{1 S}}{\rho_{W S}}+\frac{m_{c}}{G_{s}}=V
\end{aligned}
$$

$$
\mathrm{m}_{n}=\mathrm{m}_{\mathrm{n}} \cdot\left(1+\omega_{n}\right)
$$

Where $\omega^{t}$ is the new sample mud moisture content, $m_{w}$ is the added water quality, $m_{g}$ is the dry soil quality in sample, $F_{w}$ is water density, $G_{z}$ is the clay relative density, $V$ is $1000 \mathrm{ml}$ measuring cylinder volume, $m_{0}$ is the sample quality, $\omega_{0}$ is the sample moisture content.

We added a certain quality of water into the dredged sediment sample, stir for 5 minutes in $1000 \mathrm{ml}$ beaker, pour into the $1000 \mathrm{ml}$ measuring cylinder, mixed some flocculants, stirred up and down 50 times, and started timing. Then we observed the mud mixture's sedimentation process in measuring cylinder, recorded slippage of soil-water system, and watched the clear degree of liquid supernatant.

This paper took three factors into account, which were faster sediment flocculating settlin g, higher soil quality, and lower supernatant turbidity.

\section{The Effect of Sediment's Flocculating Settling and Results Analysis}

To accelerate the sedimentation rate, we adopted anionic PAM with three million molecular weight and non-ionic PAM with five million molecular weight, based on the sewage treatment plan's experience.

The technique plan was that adjusted two beakers of $1000 \mathrm{ml}$ ammonia water's $\mathrm{pH}$ for 8 to 10 , added $1 \mathrm{~g}$ anionic PAM and $1 \mathrm{~g}$ non-ionic PAM respectively to two beakers, mixed well. Then took 5mg, 10mg, 15mg, 20mg anionic PAM solution and 5ml, 10ml non-ionic PAM solution to six 1000 $\mathrm{ml}$ measuring cylinders, compared with pure soil sample, as was shown in Figs. 1 and 2.

From Figs. 1 and 2, it is clear that, 5mg anionic PAM and 10mg anionic PAM have the faster sedimentation speed, and their final moisture content tend to respectively $170 \%$ and $160 \%$. And that anionic PAM samples' speed are faster than non-ionic PAM as a whole. Also, every column sample are divided into three layers, but their clear mixed interface are not distinct. It shows that they are not good for the effect of liquid supernatant. In addition, every group can reduce their $\mathrm{pH}$, anionic PAM samples' are kept at 7, and non-ionic PAM samples' are kept at 6.5. 


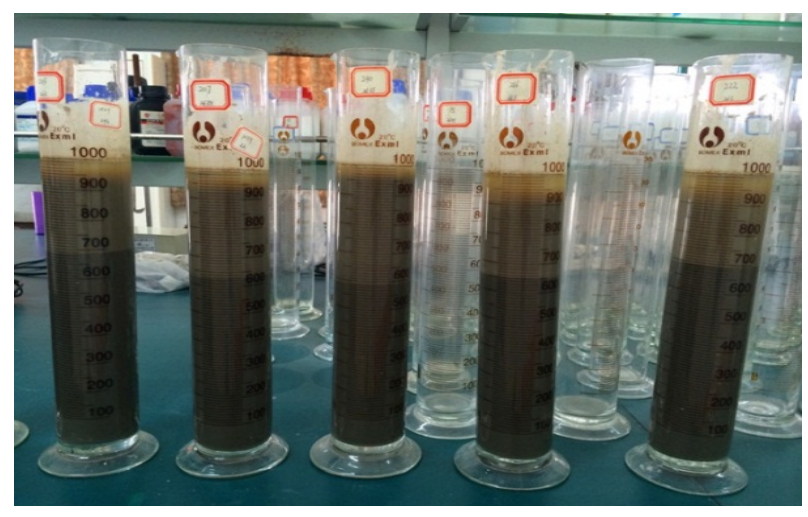

Fig 1. Settling column experiment of pure soil sample and PAM

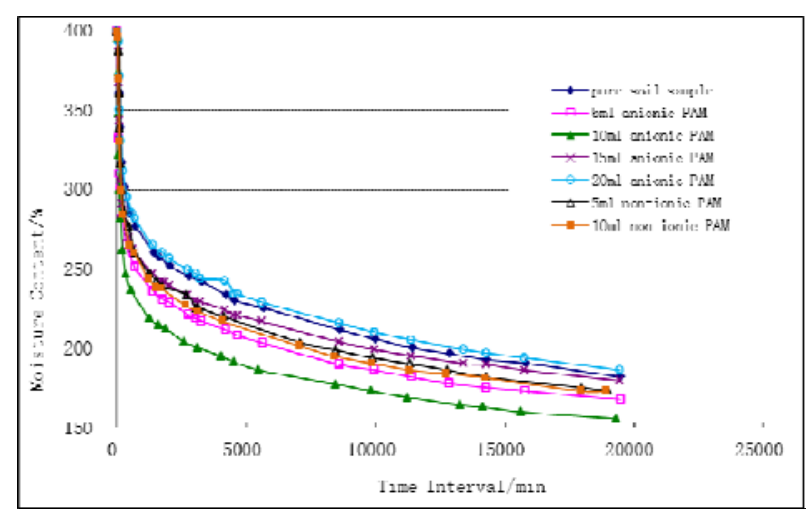

Fig 2. Effects of different kinds and amounts of PAM on dredged sediment's gravity sedimentation

\section{The Improvement of Dredged Sediment Properties and Results Analysis}

Due to the role of reservoir sediment through long-term settlement, its composition of fine soil particle is higher than other soil. To increase the soil particle size, and improve the sedimentation rate, this experiment takes $\mathrm{Na}_{2} \mathrm{CO}_{3}, \mathrm{Na}_{2} \mathrm{SiO}_{3} \cdot 9 \mathrm{H}_{2} \mathrm{O}$ and $\mathrm{CaCl}_{2}$ to improve its properties based on literature and previous experiments.

The test plan was that the dosage of $\mathrm{Na}_{2} \mathrm{CO}_{3}$ and $\mathrm{CaCl}_{2}$ was $1 \%, 2 \%$ and $3 \%$ of mud dry weight, and the dosage of $\mathrm{Na}_{2} \mathrm{SiO}_{3} \cdot 9 \mathrm{H}_{2} \mathrm{O}$ was $4 \%$. Their setting columns were shown in Figs. 3, 4, and 5.

As shown that their setting effect and defecation on sediment are very poor. $\mathrm{Na}_{2} \mathrm{SiO}_{3} \cdot 9 \mathrm{H}_{2} \mathrm{O}$ has obvious effect on the large particles, but has no clear mixed interface. Form Fig 6, it can be seen that, $\mathrm{CaCl}_{2}$ has no settlement, because $\mathrm{CaCl}_{2}$ has dispersive action. Although the sedimentation of $\mathrm{Na}_{2} \mathrm{CO}_{3}$ samples are better than others, the liquid supernatant is turbid. And their final moisture content tend to $220 \%$. It proves that they can't ensure treatment water quality. Their $\mathrm{pH}$ is about 9 , and belong to alkaline substances.

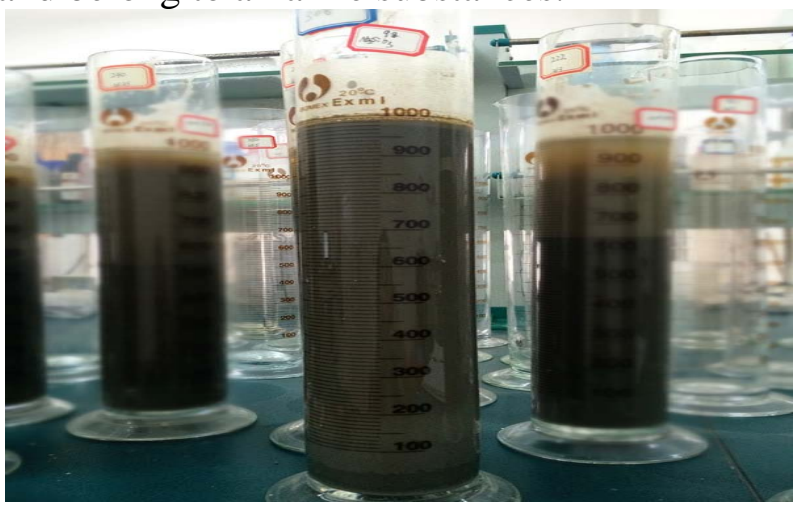

Fig 3. Settling column experiment of $\mathrm{Na}_{2} \mathrm{SiO}_{3} \cdot 9 \mathrm{H}_{2} \mathrm{O}$

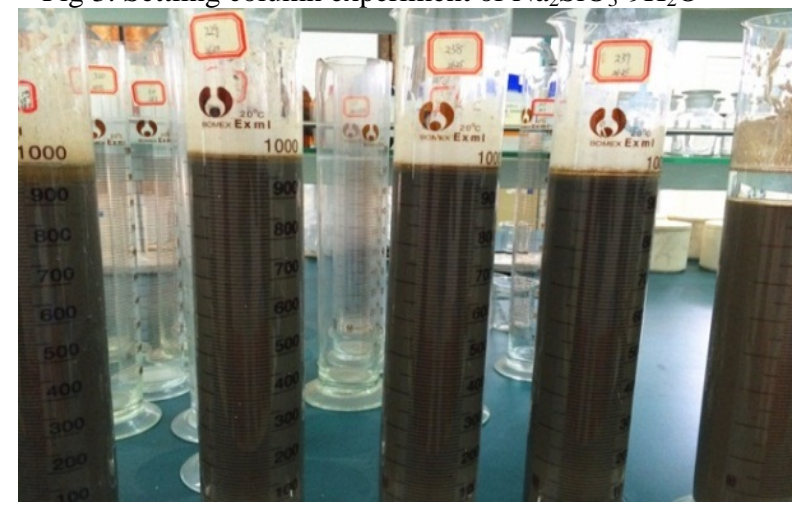

Fig 5. Settling column experiment of $\mathrm{CaCl}_{2}$

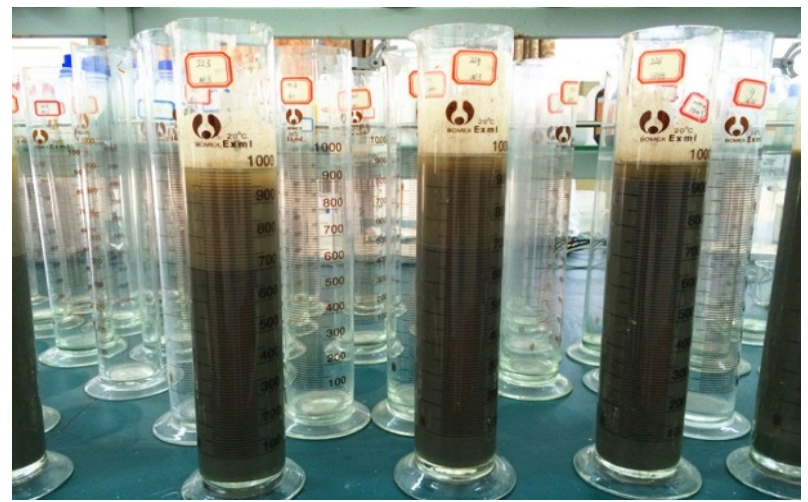

Fig 4. Settling column experiment of $\mathrm{Na}_{2} \mathrm{CO}_{3}$

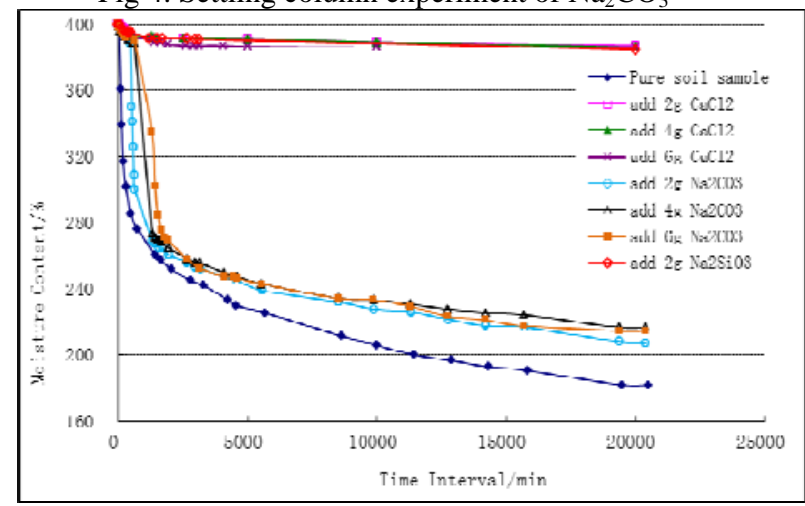

Fig 6. Effects of different kinds and amounts of $\mathrm{Na}_{2} \mathrm{CO}_{3}$, $\mathrm{Na}_{2} \mathrm{SiO}_{3} \cdot 9 \mathrm{H}_{2} \mathrm{O}$ and $\mathrm{CaCl}_{2}$ on dredged sediment's gravity sedimentation 


\section{The Improvement of Residual Water Quality and Results Analysis}

In general, $\mathrm{Fe}^{3+}$ and $\mathrm{Al}^{3+}$ can attract charges to reduce the force between impurity particles, form floccules, precipitated off. $\mathrm{KMnO}_{4}$ has strong oxidizing property, can degrade organic matters and sterilize water. Therefore, it chooses $\mathrm{FeCl}_{3}, \mathrm{PAC} \mathrm{KAlSO}_{4} \cdot 12 \mathrm{H}_{2} \mathrm{O}$ and $\mathrm{KMnO}_{4}$.

The test plan was that the dosage of $\mathrm{FeCl}_{3}$ and $\mathrm{PAC}$ was $1 \%$ of mud dry weight, and the dosage of $\mathrm{KAlSO}_{4} \cdot 12 \mathrm{H}_{2} \mathrm{O}$ was $3 \%, \mathrm{KMnO}_{4}$ was $0.2 \%$, as shown in Figs. 7, 8, and 9.

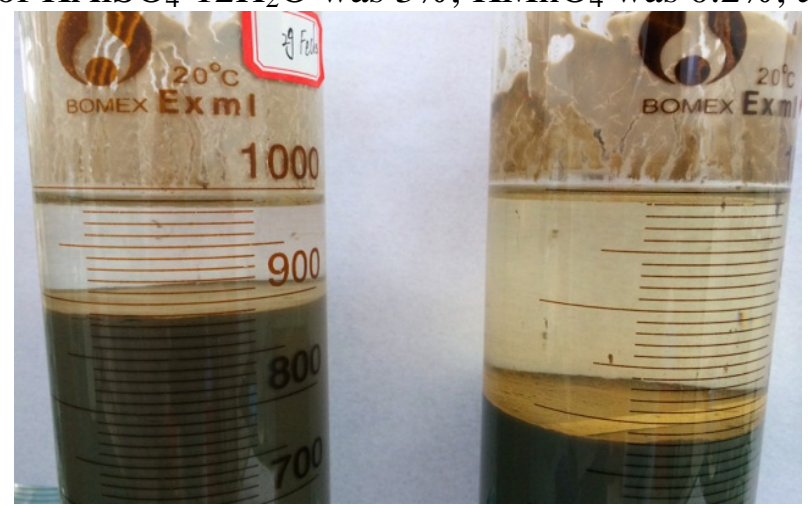

Fig 7. Settling column experiment of $\mathrm{FeCl}_{3}$ and $\mathrm{PAC}$

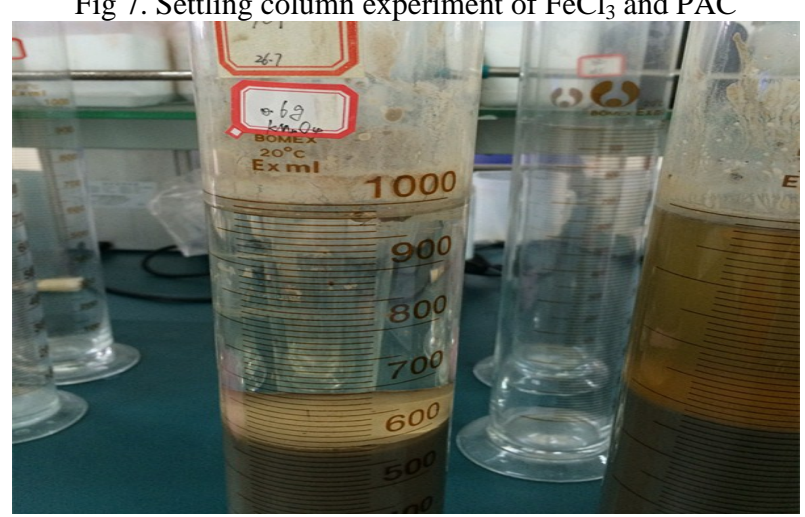

Fig 9. Settling column experiment of $\mathrm{KMnO}_{4}$

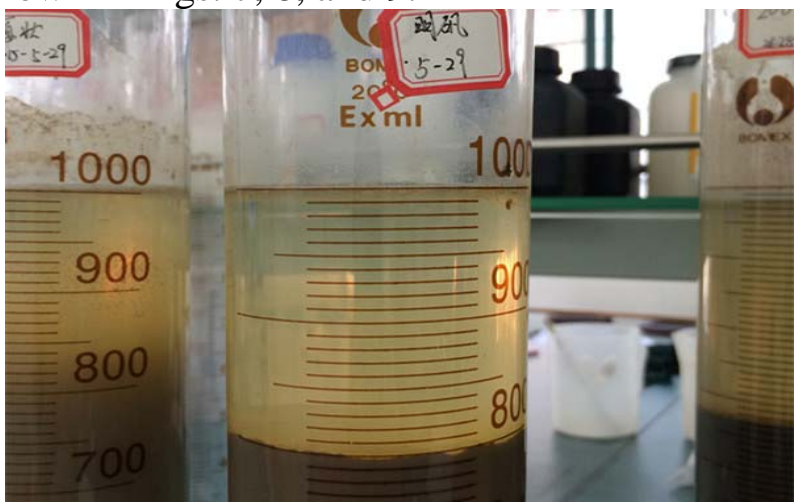

Fig 8. Settling column experiment of $\mathrm{KAlSO}_{4} \cdot 12 \mathrm{H}_{2} \mathrm{O}$

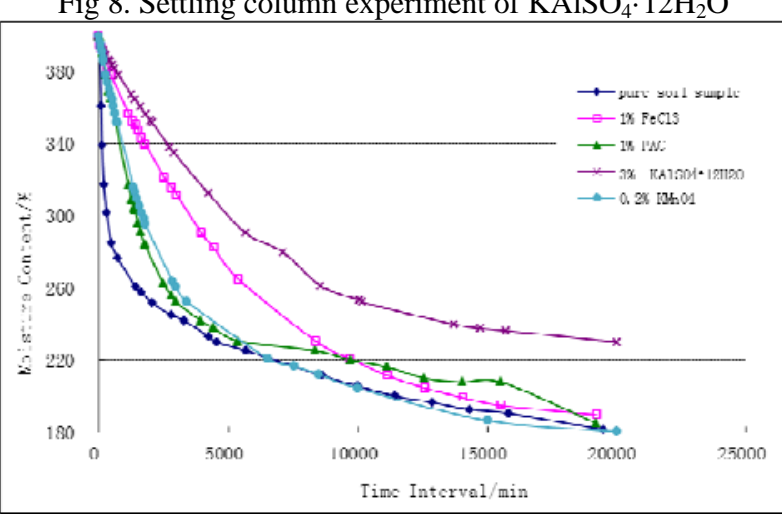

Fig 10. Effects of different kinds and amounts of $\mathrm{FeCl}_{3}, \mathrm{PAC}$, $\mathrm{KAlSO}_{4} \cdot 12 \mathrm{H}_{2} \mathrm{O}$ and $\mathrm{KMnO}_{4}$ on dredged sediment's gravity sedimentation

The solutions present acidic after mixing $\mathrm{Fe}^{3+}$ and $\mathrm{Al}^{3+}$, $\mathrm{pH}$ of $\mathrm{FeCl}_{3}$ samples are kept at 5.7, and PAC samples' are kept at 6, and $\mathrm{KMnO}_{4}$ samples' are kept at 7.4. From Figs.7, 8, 9, and 10, it can be seen that, they have good setting effect, and $\mathrm{KMnO}_{4}$ is the best, its final moisture content is about $180 \%$. Although their setting effects are a bit poorer than pure soil sample, their clear mixed interfaces are much obvious.

\section{The Effect of Organic-inorganic Compound Addition and Results Analysis}

Based on these tests and considered three factors, we choose anionic PAM, PAC, $\mathrm{Na}_{2} \mathrm{CO}_{3}, \mathrm{Ca}(\mathrm{OH})_{2}$ and $\mathrm{MgCl}_{2}$.

The test put forward five plans, including group one 5mg anionic PAM+1\% PAC, group two $5 \mathrm{mg}$ anionic $\mathrm{PAM}+1 \% \mathrm{PAC}+0.5 \% \mathrm{MgCl}_{2}$, group three $5 \mathrm{mg}$ anionic $\mathrm{PAM}+1 \% \mathrm{PAC}+1 \% \mathrm{Ca}(\mathrm{OH})_{2}$, group four $5 \mathrm{mg}$ anionic $\mathrm{PAM}+1 \% \mathrm{PAC}+0.25 \% \mathrm{Ca}(\mathrm{OH})_{2}+1 \% \mathrm{Na}_{2} \mathrm{CO}_{3}$, and group five $5 \mathrm{mg}$ anionic $\mathrm{PAM}+1 \% \mathrm{PAC}+1 \% \mathrm{Ca}(\mathrm{OH})_{2}+1 \% \mathrm{Na}_{2} \mathrm{CO}_{3}$. Their setting columns were shown in Figs. 11 and 12.

Group one and two solutions' $\mathrm{pH}$ are about 6, and present acidic. Group three to five solutions' $\mathrm{pH}$ are about 8.5, and present alkaline. From Figs 11 and 12, it can be seen that every group has obvious clear mixed interface, especially the group three. Group one's setting rate is close to group two. Group one’s final moisture content tends to 220\%, group two's tends to 210\%, group three’s tends to $230 \%$, group four's tends to $170 \%$, and group five's tends to $200 \%$. Group four has the fastest setting speed. Although group three's sedimentation is poorest, its liquid supernatant is most clear. 


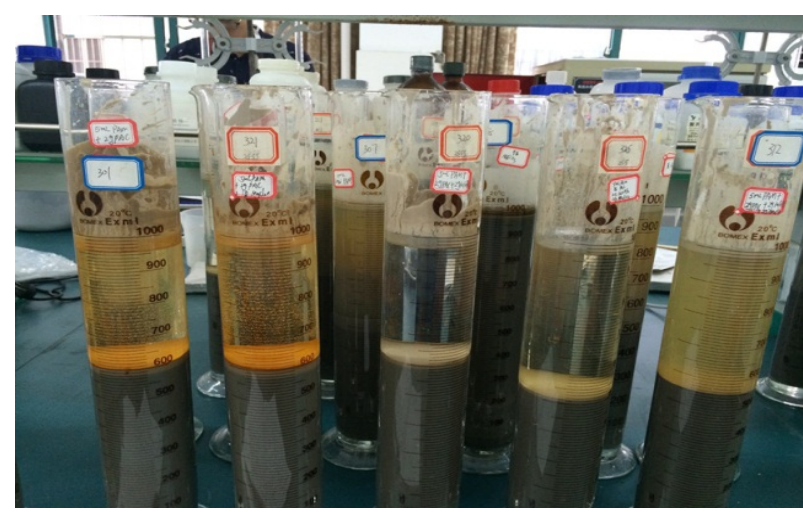

Fig 11. Settling column experiment of group one, two, three, four, and five

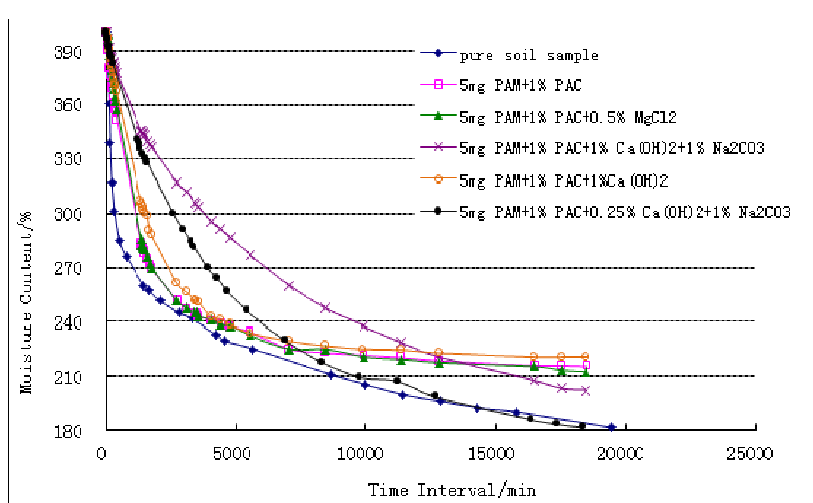

Fig 12. Effects of different kinds and amounts of organic-inorganic compound on dredged sediment's gravity sedimentation

\section{Conclusions}

(1) It turned out that the setting rate of $5 \mathrm{mg}$ anionic PAM and 10mg anionic PAM is much more fast, but their supernatant turbidity is high. Otherwise the setting rate of Flocculants such as $\mathrm{FeCl}_{3}$, PAC, $\mathrm{KMnO}_{4}$ is poorer than PAM, and their water purification ability is better. Flocculants like $\mathrm{MgCl}_{2}, \mathrm{Na}_{2} \mathrm{CO}_{3}$ and $\mathrm{Ca}(\mathrm{OH})_{2}$ have dispersion effect on fine silt, and influence the setting effect, but they can improve the soil texture. In addition, $\mathrm{Ca}(\mathrm{OH})_{2}$ can discolor the dredged sediment.

(2) Considering three aspects of sedimentation effect, argillaceous improvement, and residual water quality, this paper chooses three groups of flocculants, which are group two $5 \mathrm{mg}$ anionic $\mathrm{PAM}+1 \% \mathrm{PAC}+0.5 \% \mathrm{MgCl}_{2}$, group three $5 \mathrm{mg}$ anionic $\mathrm{PAM}+1 \% \mathrm{PAC}+1 \% \mathrm{Ca}(\mathrm{OH})_{2}$, and group four $5 \mathrm{mg}$ anionic $\mathrm{PAM}+1 \% \mathrm{PAC}+1 \% \mathrm{Na}_{2} \mathrm{CO}_{3}+0.25 \% \mathrm{Ca}(\mathrm{OH})_{2}$. Group two's moisture content is $210 \%$,group three's is $230 \%$, group four's is $170 \%$, and group three's liquid supernatant is the most clear.

(3) This study can provide a simple and feasible way for the rapid dewatering of dredged sediment in Tongji Bridge Reservoir, which would be convenient for the disposal and resource utilization of dredged sediment.

\section{Acknowledgements}

This work was financially supported by Zhejiang Province Science and Technology Agency Commonweal Technology and Social Development Project(2015C33059), Zhejiang Province Natural Science Fund project(LY3E090002), Zhejiang Province Science Planning Project(2013F10035), Zhejiang Province Water Resources Department Science Planning Project(RB1107), and Zhejiang Province Science and Technology Agency Special Support Project(2015F50G5050020).

\section{References}

[1] Chong Li, Zhigang Lv, Hongli Chen, et al. Characterzation, flocculation and dehydration of dredged sludge[J]. Chinese Journal of Environmental Engineering, 2013, 7(2):737-742. In Chinese.

[2] Reddy K. R. , Urbanek A. , Khodadoust A. P. Electroosmotic dewatering of dredged seddiments: Bench-scale investigation. Journal of Environmental Management, 2006, 78(2):200-208.

[3] Bin Lv, Kai Yang, Hanqing Hong, et al. Experimental study on the dewatering performance of east lake bottom silt. China Water and Wastewater, 2003, 19( 5) : 56- 58. In Chinese.

[4] Guiyun Liu, Peihua Jiang. Study on importance and approaches to the reutilization of river 
sediment[J]. Journal of Donghua University(Natural Science Edition), 2002， 28(1):33-36. In Chinese.

[5] Linshuang Liu, Guolu Yang, Dangwei Wang. Effects of silt density and flocculent proportion on flocculent silt dehydration[J]. South-to-North Water Transfers and Water Science \& Technology, 2009, 7(4): 57- 59. In Chinese.

[6] Pingzeng $\mathrm{Xu}$. Exploration on water-deprivation technology for urban silt removal equipments[J]. Construction Machinery Technology \& Management, 2004(3):64-66. In Chinese.

[7] Bing Ji, Xumu Xiao, Zhong Li. Dredged mud solidification disposal techniques and resource[J]. Safety and Environmental Engineering, 2010, 17(2): 54-56. In Chinese.

[8] Shao Yufang, He Chao, Qingqing Lou. Stabilization of dredge silt from West Lake[J]. Journal of Jiangsu University(Natural Science Edition), 2007, 28(5):442-445. In Chinese.

[9] Guangxing Ran, Taiguo Feng. Thoughts on disposal methods for dredging sediment in Taihu Lake[J]. China Water Resources, 2009(8):30-32. In Chinese. 